\title{
ICT Adoption in Small and Medium Enterprises: an Empirical Evidence of Service Sectors in Malaysia
}

\author{
Syed Shah Alam (Corresponding author) \\ Faculty of Business Management \\ Universiti of Teknologi MARA \\ Shah Alam 40450, Selangor \\ Tel: 603-5544-4708 E-mail: syedshah@salam.uitm.edu.my
}

\author{
Mohd. Kamal Mohammad Noor \\ Faculty of Business Management \\ Universiti of Teknologi MARA \\ Shah Alam 40450, Selangor
}

Tel: 603-5544-4789 E-mail: mkamal201@salam.uitm.edu.my

\begin{abstract}
The purpose of this study is to gain a deep understanding of the factors which influence the adoption and usage of ICT by SMEs in Malaysia. This study examines the relationship between ICT adoption and its five factors which are perceived benefits, perceived cost, ICT knowledge, external pressure and government support. The results of this study show that three factors examined are significantly important to the adoption of ICT where as perceived cost and external pressure are found to be insignificant in determining its adoption. This study provides a greater understanding of SME's perception about ICT adoption in their service business. Those SMEs who are interested in promoting their business on online may find these results helpful in guiding their efforts.
\end{abstract}

Keywords: ICT, SMEs, Melaka, Johor, Malaysia

\section{Introduction}

Today's business world has been deeply influenced by Information and Communication Technologies (ICT) and the application of ICT among business is widespread. ICT are rapidly changing global production, work and business methods and trade and consumption patterns in and between enterprises and consumers. Denni (1996) stress every business must bring ICT into their business operation and take advantage of the benefits they offer. In the developed countries including Australia and United Kingdom Small and Medium enterprises (SMEs) account for more than half of all business and over half of all employment (Kazi, 2007). Nowadays small businesses are increasingly using and adopting information and communication technology due to the advent of Personal Computer, cost-effectiveness and cheaper ICT products. Alberto and Fernando (2007) argued that the use of ICT can improve business competitiveness with internet providing numerous opportunities for SMEs to compete equally with large corporations.

As the world economy continues to move toward increased integration as a result of advances in information communications technology, and the increasing reduction in trade barriers, some of the greatest opportunities for small businesses will derive from their ability to participate in the regional and international markets (Mutula and Brakel, 2006). Adoption of the ICT is considered to be a means to enable these businesses to compete on a global scale, with improved efficiency, and closer customer and supplier relationships (Chong et al., 2001). In this respect, SMEs should consider information and communication technology (ICT) as an important approach in their business to take competitive advantage from the global markets (Mutsaers et al., 1998). Moreover, ICT is a resource of SME which may help them to access and contribute to in order to enhance its competitiveness (Swash, 1998).

Some empirical studies by Bartelsman and Doms (2000), Brynjolfsson and Yang (1996), Dedrick et al. (2003), Kohli and Devaraj (2003) and Melville et al. (2004) confirms the positive effect of information and communication 
technologies (ICT) on firm performance in terms of productivity, profitability, market value and market share. Their study also reveals that ICT has some effect in terms of intermediate performance measures, such as process efficiency, service quality, cost savings, organization and process flexibility and customer satisfaction. The introduction of ICT will offer various new investment opportunities within local industries, particular in the area of SMEs. Industries that are developing may take advantage of ICT which are being recognized by many previous studies. In fact, there is a need to accelerate the implementation of ICT to improve business performance. In order to do so, it is important to measure the key factors driving the growth of ICT and providing appropriate recommendation on this study.

This paper aims at investigating the factors that influence ICT adoption by small and medium enterprises in service industries of the southern area. A variety of internal and external factors have been identified as preventing many SMEs from implementing ICT. The study, which is reported in this paper, provides more in-depth information about the reasons why local SMEs are reluctant to adopt ICT for their business activities. Identifying the major reasons may help the industry or government to provide appropriate information and support thus enhance ICT usage. Most of the empirical research is based on large companies, and SME in fact are characterized by the lack of knowledge about the real advantages that ICT could add to their business (King, 1994; Palvia, 1994). After the discussion of ICT usage, conclusion is drawn along with significant recommendations to improve ICT utilization amongst SMEs.

The article is structured as follows. Section 1 is the introduction. Section 2 presents a literature review of ICT adoption in SMEs. Section 3 presents the conceptual framework of this study. The research design and the data collection process is presented in section 4. Section 5 presents an analysis of the results. Section 6 presents the limitation. Section 7 provides managerial implication, while section 8 discusses some conclusions.

\section{Malaysian SMEs and ICT usage}

Small and medium enterprises (SMEs) play a vital role in the Malaysian economy and are considered to be the backbone of industrial development in the country (Saleh and Ndubisi, 2006, Ramayah et. al., 2002). Small and medium sized enterprises (Hashim, 2000) are defined as firms employing full-time employees 150 or with annual sales turnover not exceeding RM25 million, and play a significant role in the country's economic development, particularly in the manufacturing sectors (Ramayah et. al., 2002). As of December 2005, a total of 600,000 SMEs were registered in Malaysia (SME bank). They contribute 27.3 per cent of total manufacturing, 25.8 per cent to value-added production, own 27.6 per cent of fixed assets, and employ 38.9 per cent of the country's workforce (SMIDEC, 2002). There are 192,527 establishments in the services sector, and 186,728 (or 96.7 per cent) of these are made up of SMEs in Malaysia (DOS). According to Yusoff (2004) the services sector grew by $6.8 \%$ in 2004, driven by higher consumer spending and a record level of tourist arrivals. Growth emanated from strong expansion in all sub- sectors with transport and communication in the lead at $8.4 \%$ followed by wholesale and retail trade, hotels and restaurants $(7.1 \%)$ and finance, insurance, real estate and business services (6.5\%). Together with new growth areas in information and communications technology (ICT), the services sector was able to maintain its premier position in terms of its share of GDP at 57.4\%.

Malaysian businesses, small and medium-sized enterprises (SMEs) have been relatively slow in web adoption. According to Lee (2005) about 30 per cent of SMEs in Malaysia have a web presence and use IT extensively in their daily operations. This reflects a poor rate of IT adoption among the estimated 600,000 local SMEs. Most SMEs perceived the barriers of implementing IT into their business operations as expensive, risky, complex procedure, lack of technical expatriate, and customer services (Yeung et al., 2003; Chong et. al., 2001; Pires and Aisbett, 2001). According to Soh et al. (1997) if SMEs in Malaysia adopt the ICT, the potential commercial functions that could be performed include, marketing themselves both locally and globally, gathering business information and consumer feedback, providing customer support and conducting electronic transactions. On the other hand, if ICT implementation is successful, it would have severe repercussions on small businesses with their limited resources (Chong et. al., 2001).

According to Lim (2006) most SMEs in Malaysia realize that ICT is critical to the productivity and performance of their companies. But, implementation and maintenance of these ICT systems is restricted due to inability to handle, owing to high staff turnover and lack of ICT project management expertise. He also stresses that many Malaysian family-based SMEs are still operating their business the conventional way. Consequently SMEs which have invested in ICT systems fail to implement and maintain these systems successfully. Similarly, Tan (2006) argues that ICT in Malaysia is facing big challenges due to the slow adoption of technology by SMEs in Malaysia. He also suggests that SMEs must learn to adopt technology to increase their global competitiveness.

\section{The conceptual framework for the study}

The conceptual model tested in this paper contains constructs that have demonstrated theoretical support, based on a number of researches done in this area in different developed and developing countries, particularly on ICT and other innovation perspective. The model examines the factors that would possibly affect the ICT adoption. The conceptual model is shown in Figure 1.

\section{Insert Figure 1 here}


The schematic diagram of the theoretical framework above is use to show the relationship between the dependent and independent variables. Essentially, the theoretical framework show above is the foundation on which the entire research is based upon.

ICT adoption is the dependent variable in this research. The dependent variable is analyzed in this research in order to find out the answer or solution to the problem i.e. what contributes the company to adopt ICT in their business? In this situation, the study has tested five independent variables i.e. perceived benefit of ICT, perceived cost of adoption, ICT knowledge and skill of the employees, external pressure, and government support that are believed to have some influences towards the dependent variable (ICT adoption) either in positive or negative way.

\subsection{Perceived benefits}

The existing literature has proved that the greater the benefits perceived by the SMEs the higher the possibility of ICT adoption. Perceived benefits should be considered as one of the factors that could affect ICT adoption in the firms. In one empirical study, Giovanni and Mario (2003) found that ICT is able to offer enterprise a wide range of possibilities for improving their competitiveness such as provide mechanisms for getting access to new market opportunities and specialized information services. According to OECD (2004) it was found that ICT is able to improve information and knowledge management inside the firm and increase the speed and reliability of transactions for both business-to-business (B2B) and business-to-consumer (B2C) transactions. Besides that, they also explained the opportunities offered by ICT, which an organization can exchange real-time information and build closer relationship with suppliers or business partners and customers. This study also found the possibility of immediate customer feedback according to the customer demand in the new markets.

Sakai (2002) study also stress that the extensive use of ICT can allow micro-enterprises with ideas and technologies to remain small and profitable or generate substantial global sales by exploiting their intellectual property over the Internet. On the other hand, Pohjola, 1998 suggests that ICT is thought to contribute to overall growth in the long-term. Generally primary motivation for the SMEs to adopt new technologies (such as the Web) is the anticipated benefits these technologies will bring to the company (Premkumar and Roberts, 1998). Nowadays SMEs have recognized the positive impacts of ICTs such as computer terminals, e-mail and Internet to the organization level as well as their applications on business performance.

According to a study by Lymer et al (1997) it stresses that ICT implementation in the organization which includes SMEs has the potential to reduce costs and increase productivity level. According to them small firms might find cost-effectiveness as a motivating factor to use Internet-commerce for improving communication with trading partners and consumers. Lauder and Westall (1997) have given their experts opinion that ICT impacts include cheaper and faster communications, better customer and supplier relations, more effective and efficient marketing, product and service development and better access to information and training. Barua (1995) study found a positive impact on ICT usage in business and it is able to increase business performance.

Since there are many perceive benefits that have been made available through adoption with ICT, there are still many organisations not taking advantage of ICT. Therefore, perceived benefits are taken into consideration as one of the factor that affects ICT adoption in SMEs.

\subsection{Cost}

The cost of adoption is an important factor in the adoption and utilization of the Web (Ernst and Young, 2001). Generally, the higher the costs adoption of the innovation, the slower the pace of innovation expansion is likely to be (Mansfield, 1968; Davis, 1979). The cost factor was studied by various Information System (IS) researchers (Seyal and Rahim, 2006; Premkumar et al., 1997; Drury and Farhoomad, 1996; Cox and Ghoneim, 1996) and found direct and significant relationship between cost and adoption of technology. The lower the cost of adoption the higher the new innovation such as the ICT will be adopted by the company and vice versa.

Perceived cost is another independent variable included in the framework. The reason perceived cost is included in the framework is because it plays an important role for SMEs in determining adoption of ICT in their business. The SMEs will less likely to adopt ICT when its initial set-up cost is high (Dixon et al, 2002). Poon \& Swatman (1996) and Reynolds (1994) stated that small businesses often have difficulty in obtaining financial resources. Any new technology like ICT may be considered too expensive to many SMEs because of their lack of financial resources (Poon and Swatman, 1999). Tidd (1997) expressed that SMEs face specific problems in the formulation of their innovation strategies due to their limited resources and range of technological competencies.

In any situation implementing ICT into SMEs need a huge amount of start-up cost. However, a ready-to-use online package integrating a new system into an existing system is very expensive for SMEs thus increase their financial burden (Mehling, 1998). According to Duncombe and Heeks (2001), survey on US SMEs found that $90 \%$ of the survey SMEs lack of finance and skills are the main constraints for organization to utilize ICT. Some of them cannot afford to buy a computer or make efficient use of it in the short or even medium period of time. 


\subsection{ICT knowledge and skill}

Recent research on ICT adoption is emphasized on SMEs and examined the factors influencing SMEs adopting ICT. According to MacGregor et al (1996), small business tends to avoid ICT into their business, if it is seen as complex to use. This is not surprising because SMEs always lack of skills amongst workforce to use ICT (Spectrum, 1997). Paul and Pascale (2003) study reveals that the ICT adoption in SME depends on the CEO/owner being the ICT decision-maker. Their findings clearly indicated that ICT adoption is positively related to firm size.

It is very important for organization to determine its employee's knowledge or skills of ICT because those knowledge or previous experiences may influence organization decision in adopting ICT. However, the ability of manager or owner in ICT's knowledge or skills is definitely increasing the opportunity of ICT use amongst SMEs. Reynolds (1994) found that small business owner/managers are unlikely to adopt more sophisticated technologies if they are not familiar with the basic ones. This is because of the limited number of employees with lack of technical knowledge. This lack of knowledge based employees might hinder or prevent technology adoption if the owner believes that this technology can only be employed using specialist staff (Reynolds, 1994). MacGregor et al. (1996) and Cragg and King (1993) also stressed that employees of small businesses tend to lack skills and expertise to use IT in their businesses. It examined that SMEs always lack of skills amongst workforce to use ICT (Spectrum, 1997). The lack of suitable technical and managerial staff with sufficient ICT expertise is another major barrier for SMEs in adopting ICT. Allison (1999) agrees that a skilled and knowledgeable work force was closely linked with the successful implementation of technology. More researchers confirm the finding such as Cragg and King (1993) found that one of the strongest inhibiting factors for small firm to implement information technology was the lack of information system knowledge.

\subsection{External pressure}

External pressure like pressure from business trading partners is one of the important predictor that has strong influence on adoption of ICT. Lacking of pressure from their trading partners, the business owner may perceived the technology as a waste of resources (Thong and Yap, 1995; Iacovau et al, 1995). It means that SMEs trading partners are not fully utilizing IT in doing business. According to Kirby and Turner (1993) dependency on customer/supplier is closely related to 'external pressure to adopt. When a major supplier or customer adopts IT, the small business owner is more likely to adopt (Kirby and Turner, 1993). Julien and Raymond (1994) and Thong and Yap (1995) also confirmed industry sector has been shown to be interested to adopt technology if competitors and trading partners or a whole industry are adopting IT, the individual small business is likely to adopt as well. Parker (1997) and Poon and Swatman (1996) studies, found that small businesses are often forced to use IT by large companies. So this could be a factor driving the use of web-commerce if their trading partners force them to use it.

\subsection{Government support}

Both industry and government bodies have a role to play in promoting and supporting small business networking and ICT. According to Doig (2000), Australian governments are committed to accessible e-commerce for SMEs, and have decided that some intervention was necessary to make participation affordable, particularly for small and remote businesses. Doig (2000) also reported that in 1998, a national framework was established to ensure all Internet based e-commerce systems used by governments in Australia and New Zealand became fully interoperable, which benefited SMEs and their access to the marketplace). This has strong industry support with most of the major e-commerce service providers now established in Australia.

Given the globalisation of the ICT industry, there is a need to understand government role in contributing to the success of ICT development. A study carried out in Israel to identify three important factors that had contributed to the creation ICT industry in Israel (Vinig et al., 1998). According to them the Israeli government placed support of the ICT industry played an essential role in initiating the financial base. Their government also initiated a list of programs which will lead to the establishment of financial base for Israel ICT industry. At the same time, programs alone could not lead to a successful ICT industry. The other government support in ICT is government's tax incentives. This program support start-ups ICT companies to attract foreign investors to form a strong international oriented companies was created locally.

\section{Hypotheses}

A hypothesis is a statement or proposition that can be tested by referring to a collection of empirical studies. Hypotheses are usually stated in a form that predicts either the differences or association between two variables under study (Churchill and Brown, 2004). Development of a hypothesis involving causal ordering where possible and measurable would be useful in guiding the analysis strategy. Often such hypotheses can be made if the meaning of an item is carefully analyzed within a chronological context.

A null hypothesis predicts there is no difference between the tested groups in relation to some variable, or that there is no relationship between two variables (Malhotra, 2004). Null hypothesis in this research is noted as $\mathrm{H}_{0}$ while alternate hypothesis is noted as $\mathrm{H}_{1}$. It is important to note that a researcher can never actually prove that an alternate hypothesis is 
true (Malhotra, 2004) because of the many potential errors, either known or unknown, involved in the measurement of variables and the selection of research subjects. It is usual for the researcher to test whether the null is probably true or probably false to accept the alternate hypothesis as the alternate logical solution of the research problem (Churchill and Brown, 2000)

The following hypotheses are derived from the relationships found from the previous literatures.

\section{Insert Table 1 here}

\section{Methods}

\subsection{Samples and procedures}

A survey instrument was formulated to obtain feedback from SMEs in Malaysia, assessing their awareness, receptivity and adoption of ICT in their business. In order to focus on SMEs, lists were sought from the Small and Medium Industries Development Corporation (SMIDEC) in Malaysia web site. As such, the surveys sent out were personally addressed to the owner and or manager of each of SMEs. Due to the exploratory nature of this study, a cross sectional approach was undertaken to measure firms' responses regarding adoption of ICT.

The population of this study comprises all SMEs from service sectors in Melaka and Johor Bahru states in Malaysia that are registered under Small and Medium Industries Development Corporation (SMIDEC). The target groups were SMEs considered based on the number of employees in the industry is most commonly used in management research (Ghobandian and Gallear, 1996; Haksever, 1996; Terziovski et. al., 1997). The SMIs industries are classified as those industries with total workforce of less than 150 employees (SMIDEC, 2002). Data were gathered based on mail and personal administered questionnaire. A packet of 400 survey instruments, enclosing a return envelop were sent to randomly selected from insurance, banking and finance, health and medical, education, tourism, logistics, professional management, IT related service and advertising sector. The respondents for this study were targeted to be the owner or manager of the organisations because they always had the chance to deal with ICT in their working position.

To maximize the return rate, three subsequent reminders were sent over telephone and the mail lists maintained by SMIDEC after the initial surveys were mailed. Telephone inquiries were conducted only three weeks later as a last resort for those SMEs that had not responded. The response rate for the survey was 48.25 per cent (193 responses). Due to missing values for at least two sections of the responses 13 samples were discarded from this research and finally 180 samples were then processed and analyzed.

\subsection{Statistical tools}

Bivariate frequency distribution of the respondents, according to types of businesses, ownership of the company, respondent's position, computer ownership, Internet access, length of Internet access, and operating system was presented. Data were collected on demographic variables are processed and reported in percentage through the descriptive analysis. Descriptive analysis refers to the transformation to describe a set of factors that will make them easy to understand and interpret (Sekaran, 2000; Zikmund, 2000).

\subsection{Test of reliability, validity and identification of factors}

\subsubsection{Reliability}

The measurement of reliability provides consistency in the measurement of variables. Internal consistency reliability is the most commonly used psychometric measured assessing survey instrument and scales (Zhang et al., 2000). Cronbach alpha is the basic formula for determining the reliability based on internal consistency Kim and Cha, (2002). The values of alpha for perceived benefits yields a reliability co-efficient of 0.876 as shown in Table I. this value far exceeds the minimum standard of 0.7 set by Nunnally (1978). The value of 0.876 generates a strong indication that there is an internal consistency in the measurement. Similarly, the six statements measure for cost generates a Cronbach Alpha value of 0.861 , highlighting an internal consistency in the measurement.

The values of alpha obtained for ICT knowledge and skill is 0.856 , which suggest that scale is reliable for use in this study. The measures for external pressure gave Cronbach Alpha values of 0.878 also being supportive. The reliability coefficient for government support (0.792) indicates high internal consistency among its statements. This is consistent with reports by Nunnally (1978). Since the Cronbach's alpha values are in between 0.792 to 0.878 and all above cut off limit, that is 0.7 , the constructs are therefore deemed to have adequate reliability.

\subsubsection{Test for construct validity: factor analysis}

A factor analysis was conducted in order to develop factors that help in explaining the role of experience and reference group in online brand trust. As suggested by Hair et al., (1995), six factors were identified for the factor analysis using the eigen value criteria that suggest extracting factors with an eigenvalue of greater than 1.0. In conducting the factor analysis we followed Hair et al (1995) and Alfansi and Sargeant (2000). The rotated factor matrix is displayed in Table II. The five factors identified explain 62.31 percent of the total variance. The extraction method used was principal axis 
factoring with Varimax rotation. This method has been widely accepted as a reliable method of factor analysis (see, Alexander and Colgate, 2000). In our survey, the Kaiser-Meyer-Olkin (KMO) measure of sampling adequacy score (0.92) was well above the recommended 0.5 level (Malhotra, 1999) suggested that the data may be factorable. Moreover, the Bartlett's test of sphericity indicated that there was adequate correlation among the chosen variables $\left(\mathrm{X}_{(406)}^{2}=\right.$ 2945.30, $\mathrm{p}<0.01)$.

However one item of perceived benefit, one item of good online experience loaded together with other items is considered as insignificant and not meaningful as it is of low correlations decided to remove from all further analysis.

\section{Insert Table 2 here}

\subsubsection{Normality of Data and Multi-collinearity}

This study involves a relatively large sample (180 SMEs) and therefore, the Central Limit Theorem could be applied and hence there is no question on normality of the data. Two major methods were utilized in order to determine the presence of multicollinearity among independent variables in this study. These methodologies involved calculation of both a Tolerance test and Variance Inflation Factor (VIF) (Kleinbaum et al, 1988). The results of these analyzes are presented in Table 4. As can be seen from this data, i) none of the Tolerance levels is <or equal to .01; and ii) all VIF values are well below 10. Thus, the measures selected for assessing independent variables in this study do not reach levels indicate of multicollinearity. The acceptable Durbin - Watson range is between 1.5 and 2.5. In this analysis Durbin - Watson value of 1.722, which is between the acceptable ranges, show that there were no auto correlation problems in the data used in this research. Thus, the measures selected for assessing independent variables in this study do not reach levels indicate of multicollinearity

\section{Result and analysis}

In this section, the results and analysis of the empirical study are presented and discussed. The main aim of this analysis is to identify the major factors that influence ICT adoption by SMEs in Malaysia. First the socio-economic characteristics of the respondents are analyzed. Then, the factors those related with ICT adoption are discussed. Finally, the some recommendations are given to the managerial and government context.

\subsection{General information of the respondents}

Table III shows the profile of the responding companies including types of businesses, ownership of the company, respondent's position, computer ownership, Internet access, length of Internet access, and operating system for the respondents. The study in this research actually provides the frequency distribution of each variable for the sample respondents.

The majority of the surveyed companies are wholesale and retail business (47.7\%) while it is found 170,046 companies and covering 88.8 per cent of all enterprises in Malaysia (Saleh and Ndubisi, 2006). Most of the respondents' company in this study was from local ownership which was 88.3 percent or 159 out of 180 respondents. On the other hand, foreign ownership company only constituted 21 companies which were 11.7 percent. More than 50 per cent (53.9\%) of the surveyed middle manager and below represents higher percentage amongst all respondents which were 97 respondents. However, executive became second highest in this study, which was 27.8 percent, followed by Manager, 12.8 percent. In addition, top level management such as CEO, and owner of the company was least participate in this study which only contribute 5.6 percent and 10 out of 180 respondents. Moreover questionnaires were frequently answered by lower level management because top level management always lack of time in answering questionnaire. Even though about $57.22 \%$ of the respondents indicated that their companies did have computer, but 86 of the companies have Internet connection where more than $57.28 \%$ of them had been using Internet less than 5 years, and $42.72 \%$ using Internet for more than 5 years.

The results indicate that most of the companies adopt Windows XP for their computer system. There were 69 out of 103 companies using Windows XP which carried 66.99 percent and 27 companies were using Windows 2000/98 for their operating system on respondents' work computer. The Mac OS X was using in some organization but their usage was lower which accounted for 6.8 percent only. The main reason most organization choosing Windows XP as their operating system might be the user-friendly of this system.

\section{Insert Table 3 here}

\subsection{Regression analysis}

The data were analysed using multiple linear regression analysis following the guidelines established by Hair et al. (1998). The purpose of regression analysis is to relate a dependent variable to a set of independent variables (Mendenhal and Sincich, 1993). Table IV present the result of predictors of ICT adoption. The regression coefficient of independent variables on ICT adoption was estimated. The overall model is significant at the $1 \%$ level. The independent variables explain $53 \%$ of the variance in the ICT adoption. Of the independent variables, perceived benefits $(+)$, ICT knowledge and skill $(+)$ and government support $(+)$ are the only predictors statistically different from zero and had a 
significant and direct effect on ICT adoption intention. The remaining perceived cost (-) and external pressure (+) had no significant direct effect on ICT adoption intention. Table IV presents the results of the individual hypotheses being tested.

\section{Insert Table 4 here}

\section{Discussion}

In this section, we will present and discuss the conclusions derived from our results and we will make consistently a series of recommendations for government and SMEs management.

According to the results, a perceived benefit has a strong, significant relation to ICT adoption. It is expected since past literature has consistently shown that perceived benefit has a significant and positive influence on the ICT adoption (Wang and Tasai, 2002; Grover and Goslar, 1993; Bingi et al., 2000). The subscale mean value (not shown here), indicate Internet will allow company to cross international boundary. However, respondents are not found computer simplify their daily business operation. The results obtained in the study are supported by Premkumar and Roberts, (1998) on ICT adoption by SMEs.

Usage of ICT applications in business purposes brings numerous advantages for its user to business area. At present, most of the businessmen are curious to find out the benefit that they can gain through appropriate ICT implementation. Implementing ICT in the organisation will be able to offer businesses a wide range of possibilities for improving their competitiveness such as provide mechanisms for getting access to new market opportunities and specialized information services Giovanni and Mario (2003). Moreover, businesses are able to receive immediate customer feedback which allows companies to react fast to changing customer demands and recognizing new market niches.

Some respondents would also like to agree with the use of Internet on business will be important for future company's progression. Most of the respondents believe that doing business over the Internet will generate desired returns in terms of profit (mean value).

Perceived cost was not found to have any direct impact on ICT adoption. One possible reason is that recently, Malaysian government has been providing all types of financial support to the SMEs, due to the promotion of ICT by the government through Multimedia Super Corridor (MSC) and Small and Medium scale Industries Development Corporation (SMIDEC). The SMEs have options to get financial support for the costs of ICT include investment in the process of its implementation in their businesses (networks, PCs, data storage, demonstration, servers, software/hardware and other peripheral devices). These conditions can consequently lead to an unimportance of perceived cost of ICT adoption.

The relation between ICT knowledge and skill of the employees with ICT adoption is significant. It is important for the organisation to determine its employee's knowledge or skills of ICT because those knowledge or previous experiences may influence organisation decision in adopting ICT. Moreover, the ability of manager or owner in ICT's knowledge or skills is certainly increasing the opportunity of ICT use among businesses. Reynolds et al. (1994) found that small business owner/managers are unlikely to adopt more sophisticated technologies if they are not familiar with the basic ones. This supported by Mehrtens et al. (2001) who demonstrated clearly that employees with technological skill are particularly encourage firms to recognize and implement ICT into the businesses. This is a principal internal motivating factor for business to adopt ICT.

Past studies found that external pressure play a critical role IT adoption by small firms (Beatty, 1998; Webster, 1994; Swatman and Swatman, 1991). But this study found show that external pressure has a positive relationship with ICT adoption intentions, this relationship is not significant (please refer Table IV). One possible reason is that Malaysia SMEs are not involved in the global business. Due to that there is not much pressure from customer or suppliers to adopt ICT in their business operation.

According to the result, government support has a significant and strong positive relation to ICT adoption. According to Stoneman and David, (1986) the impact of government policies and initiatives has been shown to have direct and indirect stimulation to the supply of information which produces faster technology diffusion. For example, governmental efforts to establish a national information infrastructure in US, Singapore and Malaysia have shown that both governments provide a legitimate and positive leadership role in developing the information infrastructure in its effort to digitize its economy (Kettinger, 1994; Tan, 1998).

\section{Limitations and future directions}

Like other empirical studies, this study is not without its limitations. Our sample consisted of SMEs in Melaka and Johor Bahru states in Malaysia may limit the generalizability of the results. Although several technology adoption studies focused on the zone basis ( Van Beveren and Thomson, 2002; Cloete et al., 2002), state based respondents, such as experience using technology, differ from state to state from overall population of SMEs. The sample size itself is relatively small. The study can be strengthened by increasing the sample size and including participants in other 
geographical areas. With an increased sample size, a more detailed empirical analysis among the independent variables and the variables that have multiple categories can be performed. Potential correlations between some of the independent variables (e.g. gender, race, education level of the manager) need to be reported in a future study.

\section{Implications}

\subsection{Implications for research}

This study presents an introductory research that explains 52 per cent of the variance in SMEs adoption of EC. This research can serve as a starting point for other ICT adoption research, while encouraging further exploration and integration addition adoption constructs. Future research needs to focus on a larger cross section and more diversified random samples to verify the findings of the current study. Moreover, to further clarity of the factor influence on ICT adoption in the businesses, Technology Acceptance Model (TAM) and or other model could be used. Future inquiries could also examine the causal relationships between factors and SMEs' perceive overall ICT adoption by employing a structural equation modeling technique. In addition, future research needs to examine ICT adoption in the context of cross-national differences.

\subsection{Implications for practice}

The study reveals five significant indicators of SMEs' intention to adopt ICT in their business. Government agencies like MCMC, MDeC, SMIDEC, and other government agencies should create better awareness of the benefits of EC to encourage higher rate of adoption. It can be done by having seminars or induction sessions to allow SMEs to evaluate their new inventions. In order to receive greater responses towards ICT adoption, it is recommended that authority should give certificates as a token and financial support to attend the seminar. They could establish a close link with all SMEs and get continuous feedback from them in order to identify the problem areas and take necessary actions to rectify them. Another way to enhance the to use of ICT in the SMEs sectors, that the government should enforce standardized, consistent and uniform policies in all SMEs sectors, agencies or subsidiaries in implementing ICT system. As it is found in this study, respondents mentioned ICT is a complex system, the system should be made as user-friendly as possible as not all users are familiar with computers and the Internet, especially the old SMEs. Providing online help and giving end users the choice of their preferred language will ease their usage. Management of SMEs should provide adequate pre-training to their employees on how to use ICT systems in business at all levels so that the employees should get comfortable with its use. Security of information must be ensured with the help of the restricted access level of passwords.

\section{Conclusion}

The purpose of this study is to investigate factors affecting intention to adopt ICT in the SMEs of two states in Malaysia. This study also contributes to and extends our understanding of the Internet as a medium for commercial use in the service arena, identifying the rationales for adopting or rejecting the ICT by the SMEs. From a managerial viewpoint, the findings provide support for investment decisions, and for decisions relating to the development of Internet services that address and take the concerns and needs of companies into consideration.

The research was done under theoretical framework developed based on the previous study. The multiple regression analysis shows that perceived benefits, ICT knowledge and skill, and government support are significant elements of ICT adoption. The model explains 52 per cent of the variance in SMEs intention to adopt ICT. As Malaysian government grows in importance and priority for business worldwide, an understanding of the factors that influence SMEs adoption of the ICT is invaluable.

\section{References}

Alberto, B.M. \& Fernando, L.L. (2007). A firm-level analysis of determinants of ICT adoption in Spain. Technovation, 27, 352-366.

Alexander, N. \& Colgate, M. (2000). Retail financial services: transaction to relationship marketing. European Journal of Marketing, 34 (8), 938-953.

Alfansi, L. \& Sargeant, A. (2000). Marketing segmentation in the Indonesian banking sector: the relationship between demographics and desired customer benefits. International Journal of Bank Marketing, 18 (2), 64-74.

Allison, I.K. (1999). Information systems professionals' development: A work-based learning model. Journal of Continuing Professional Development, 2(3), 86-92.

Bartelsman, E.J., Doms, M. (2000). Understanding productivity: lessons from longitudinal Micro Data. Journal of Economic Literature, 38 (3), 569-594.

Barua, A., Kriebel, C.H. \& Mukhopadhyay, T, (1995). Information Technologies and business value: An analytic and empirical investigation. Information Systems Research, 6(1), 3-23.

Beatty, R. C., Shim, J.P., \& Jones, M.C. (2001). Factors influencing corporate web site adoption: a time-based assessment. Information and Management, 38, 337-354. 
Bingi, P., M. \& Khamalah, T. (2000). The challenges facing global E-commerce. Information Systems Management (Fall), 26-34.

Brynjolfsson, E. \& Yang, S. (1996). Information technology and productivity: a review of the literature. Advances in Computers, 43, 179-214.

Charchill, G. A. and Brown, Tom. J. (2000). Basic Marketing Research, Thomson Corporation, USA.

Chong, S., Pervan, G., \& Bauer, C. (2001). Implementation Success of Internet-based Electronic Commerce for Small-and Medium-sized Enterprises in Australia. $14^{\text {th }}$ International Bled Electronic Commerce Conference, Bled, Slovenia, June 25-26.

Cloete, E. Courtney, S. \& Fintz, J. (2002). Small Business Acceptance and Adoption of E-Commerce in the Western-Cape Province of South Africa, EJISDC, 10 (4), 1-13.

Cox, B. \& Ghonein, S. (1996). Drivers and barriers to adopting EDI: A Sector Analysis of UK Industry. European Journal of Information Systems, 5, 24-33.

Cragg, P.B. \& King, M. (1992). Information system sophistication and financial performance of small engineering firms. European Journal of Information Systems, 1(6), 417-426.

Davis, S. (1979). The Diffusion of Process Innovations, Cambridge: Cambridge University Press.

Dedrick, J., Gurbaxani, V., \& Kraemer, K.L. (2003). Information technology and economic performance: a critical review of the empirical evidence. ACM Computing Surveys, 35 (1), 1-28.

Denni, A.R. (1996). Information exchange and use in group decisions making: You can lead a group to information, but you can't make it think. MIS Quarterly, 4(2), 433-457

Dixon, T., Thompson, B. \& McAllister, P. (2002). The value of ICT for SMEs in the UK: a critical literature review, Report for Small Business Service research programme, The College of Estate Management. [Online] Available: www.sbs.gov.uk/SBS_Gov_files/researchandstats/value_of_ICT_for_SMEs_UK.pdf. (July 26, 2006).

Doig,L. (2000). Making e-commerce affordable. Australian CPA, 70(6).

Drury, D.H. \& Farhoomad, A. (1996). Innovation Adoption of EDI. Information Resource Management Journal, 9 (3), 5-13.

Duncombe, R. and Heeks, R. (2001). Information and Communication Technologies and small Enterprise in Africa. Lesson from [Online] Available: http://www.sed.manchester.ac.uk/idpm/research/is/ictsme/full/section2.doc, (June 12, 2007).

Ernst \& Young (commissioned by the National Office for the Information Economy (NOIE) of Australia) (2001), Advancing with E-commerce, [Online] Available: Http://www.noie.gov.au

Ghobandian, A., \& Gallear, D.N. (1996). Total quality management in SMEs. Omega, 24(1), 83-106.

Giovanni, F. \& Mario, A. (2003). Small company attitude towards ICT based solutions: some key-elements to improve it. Educational Technology \& Society, 6 (1).

Grover, V. \& Goslar. (1993). The Initiation, Adoption and Implementation of Telecommunications Technologies in US Organisations. Journal of Management Information System, 10 (1), 141-163.

Hair, J.F., Anderson, R.E., Tatham, R.L., \& Black, W.C. (1998). Multivariate Data Analysis, 5th ed., Pearson Education, Upper Saddle River, NJ

Haksever, C. (1996). Total Quality Management in the small business environment. Business Horizons, 39 (2), 33-40.

Hashim, M.K. (2000). SME's in Malaysia: Past, Present and Future. Malaysia Management Review, 35(1), 22-32.

Iacovou, C., Benbasat, I. \& Dexter, A. (1995). Electronic Data Interchange and small organizations: Adoption and impact of technology. MIS Quarterly, 19(4), 465-485.

Julien,P.A. \& Raymond,L. (1994). Factors of new technology adoption in the retail sector. Entrepreneurship Theory and Practice, 18(4), 79-87.

Kazi, A.U. (2007). Small and Medium Business Enterprises and the use and adoption of Information and Communication Technology: a study of Legal Issues and Legal Perspectives. International Journal of Organisational Behaviour, 12(1), 144-160.

Kettinger, J. (1994). National infrastructure diffusin and the U.S. information super highway. Information and Management, Amsterdam, (December) 27(6), 357-369.

Kim, W.G. \& Cha, Y. (2002). Antecedents and consequences of relationship quality in hotel industry. Hospitality Management, 21, 321-338. 
King, W.R., \& Teo, T.S.H. (1994). Facilitators and inhibitors for the strategic use of information technology. Information and Management, 27, 71-87

Kirby, D. \& Turner, M. (1993). IT and the small retail business. International Journal of Retail and Distribution Management, 21 (7), 20-27.

Kleinbaum, D. G., Kupper, L. L., \& Muller, K. E. (1988). Applied Regression Analysis and Other Multivariate Medhods, Boston: PWS.

Kohli, R., Devraj, S. (2003). Measuring information technology payoff: a meta-analysis of structural variables in firm-level empirical research. Information System Research, 14 (2), 127-145.

Lauder,G. and Westhall,A. (1997).Small firms on-line. Commissions on Public Policy and British Business.

Lim, T.M., (2006), Outsorucing to Ensure Successful ICT Systems Implementation and Maintenance. [Online] Available: http: www.infotech.monash.edu.my/news/media.html, (August).

Lymer, A. (1997). The Internet and Small businesses: a study of impacts. Fifth European Conference on Information System.

MacGreor. (1996). Attitudes of Small Business to the Implementation and use of IT: are we basing EDI Design Initiatives for Small Business on Myths? $9^{\text {th }}$ International EDI-IOS Conference.

Malhotra, N.K. (2004). Marketing Research: An Applied Orientation, Pearson Education Inc, Upper Saddle River, New Jersey.

Mansfield, E. (1968). Industrial Research and Technological Innovation: An Econometric Analysis, Norton, New York . Mehling, M. (1998). Small businesses are eager to sell wares on the Web. Computer Reseller News, 794, 87-94.

Mehrtens, J., P. B. Cragg \& A. M. Mills. (2001). A Model of Internet Adoption by SMEs. Information \& Management, 39, 165-176.

Melville, N., Kraemer, K.L. and Gurbaxani, V. (2004). Information technology and organizational performance: an integrative model of IT business value, MIS Quarterly, 28 (22), 283-322.

Mendental, W. \& Sincich, T. (1993). Second Course in Business Statistics, Dallen/Macmillian, New York

Mutsaers, E-J., H. van der Zee, \& H. Giertz. (1998). The Evolution of Information Technology. Information Management and Computer Security, 6(3), 115-26

Mutula, S.M. \& Brakel, P.V. (2006). E-readiness of SMEs in the ICT sector in Botswana with respect to information access. The Electronic Library, 24(3), 402-417.

NSDC, National SME Development Council, Definitions for Small and Medium Enterprises in Malaysia. [Online] Available: http: www.mirc.org.my/elibrary/sme_definitions_english.pdf (May, 2007)

Nunally, J.C. (1978). Psychometric Theory. $2^{\text {nd }}$ Edition, McGraw Hill, New York, NY

O'Callaghan, R., Kaufmann, P.J. \& Konsynski, B.R. (1992). Adoptin correlates ahd share effects of electronic data interchange systems in marketing channels. Journal of Marketing, 56, 45-56.

OECD. (2004). The Economic Impact of ICT - Measurement, Evidence and Implications, OECD, Paris.

OECD. (2002). Measuring the Information Economy, OECD Paris.

Palvia, P., Means D.B., \& Jackson W. M. (1994). Determinants of computing in very small businesses. Information and Management, 27, 164-174.

Parker,C.M. (1997). Educating Small and Medium Enterprises about Electronic Data Interchange: Exploring the Effectiveness of a Business Stimulation Approach. Department of Information Systems.

Pires, G.D., \& Aisbett, J. (2001). A dual Marketing and Informational Perspective to E-Commerce Adoption. The Newcastle University Research Publications.

Pohjola, M., (1998). Information Technology and Economic Development: An Introduction to the Research Issues, Research Paper, 153, World Institute for Development Economics Research.

Poon, S. \& Swatman, P.M.C. (1999). A longitudinal study of expectations in small business Internet Commerce. International Journal of Electronic Commerce, 3(3), 21-33.

Poon,S. \& Swatman, P.M.C. (1996). Electronic networking among small business in Australia -an exploratory study. International Conference, 446-460.

Premkumar, G. Ramamurthy, K. \& Crum, M. (1997). Determinants of EDI Adoption in the Transportation Industry. European Journal of Information Systems, 6, 107-121. 
Premkumar, G., \& Roberts, M. (1999). Adoption of new information technologies in rural small businesses, Omega, 27 (4), 467-484.

Ramayah, T. \& Koay P. L. (25-27 $7^{\text {th }}$ October, 2002). An Exploratory Study of Internet Banking in Malaysia. The proceedings of The $3^{\text {rd }}$ International Conference on Management of Innovation and Technology (ICMIT '02 \& ISMOT '02), Hangzhou City, P. R. China.

Reynolds,W., Savage,W. \& Williams, A. (1994). Your Own Business: A Practical Guide to Success, ITP.

Sakai, K. (2002). Global Industrial Restructuring: Implications for Small Firms, STI Working Papers. 4, OECD, Paris, [Online] Available: http://www.oecd.org/sti/working-papers

Saleh, A.S., \& Ndubisi, N.O. (2006). An Evaluation of SME Development in Malaysia. International Review of Business Research Papers, 2(1), August, 1-14.

Sekaran, U. (2000). Research Methods for Business, 3rd ed., Wiley Publications, New York, NY.

Seyal, A. H. \& Rahim, M.M. (2006). A Preliminary Investigation of Electronic Data Interchange Adoption in Bruneian Small Business Organisations. The Electronic Journal of Information Systems in Developing Countries, 24 (4), 1-21.

SMIDEC. (2002). SMI Development Plan (2001-2005), Percetakan Nasional Malaysia Berhad, Kuala Lumpur.

Soh, C., Quee, F.C., \& Reid, E. (1997). The use of Internet in Business: experience of early adopters in Singapore, Internet Research. Electronic Networking Application and Policy, 7 (3), 217-228.

Sohal A. (1999). Introducing new technology into a small business: a case study. Technovation, 19, 187-193.

Spectrum (1997). Moving into the Information Society, HMSO, London

Stoneman, P.L. \& David, P.A. (1986). Adoption Subsidies vs Information Provision as Instruments of Technology Policy. Economic Journal, Royal Economic Society, 96 (380a), 142-50.

Swash, G. (1998). UK business information on the Internet. New Libarary World, 99(1144), 238-242.

Swatman, P. \& Swatman, P. (1991). Electronic Data Interchange: Organisational Opportunity, Not Technical Problem, in Databases in the 1991's, Srinivasan, B. and Zeleznikow, J. (eds). World Scientific Press, Singapore, 354-374.

Tan, C. (2006). Towards Progress. Computerworld Malaysia, July 2006.

Tan, M. (1998). Creating the digital economy: perspectives from Singapore, Electronic Commerce in the Information Society, Proceedings from the $11^{\text {th }}$ International Bled Electronic Commerce Conference, Bled, Slovenia, June 8-10.

Terziovski, M., Samson, D. \& Dow, D. (1997). The business value of quality management systems certification. Evidence from Australia and New Zealand. Journal of Operations Management, 15 (1), 1-18.

Thong, J., C. Yap, (1996). Information technology adoption by small business: An empirical study, In Diffusion and adoption of information technology, ed.K. Kautz and J. Pries, pp. 160-175. London: Chapman \& Hall.

Tidd,J.,Bessant,J. \& Pavitt,K.L. (1997). Integrating Technological. Market and organizational Change.

Tornatzky, L. G., \& Klein, K. J. (1982). Innovation Characteristics and Innovation Adoption-Implementation: A Meta-Analysis of Findings. IEEE Transactions on Engineering Management, 29(1), 28-45.

Van Beveren, J. \& Thomson, H. (2002). Global Perspective: The Use of Electronic Commerce by SMEs in Victoria, Australia. Journal of Small Business Management, 40 (3), 250-253.

Vinig, T., Blocq, R., Braafhart, J. \& Laufer, J. (1998). Developing A Successful Information and Communication Technology Industry: The role of venture capital, knowledge and the government, PrimaVera Working Paper Series (98-01), Universiteit van Amsterdam. [Online] Available: http://primavera.fee.uva.nl/PDFdocs/98-01. pdf(January, 22, 2008).

Wang, J.c. \& Tsai, K.H. (2002). Factors in Taiwanese Firms' Decisions to Adopt Electronic Commerce: An Empirical Study, Blackwell Publishers Ltd, 2002, 108 Cowley Road, Oxford OX4 IJF, UK.

Webster, J. (1994). EDI in a UK Automobile Manufacture: Creating Systems, Forming Linkages, Driving Changes. The Seventh Electronic Data Interchange Conference Proceedings, Bled, Slovenia, Yugoslavia.

Yeung, M.A., Shim, J.P., \& Lai, A.Y.K. (2003). Factor Affecting E-Commerce Adoption: An empirical Evidence. Communication of the ACM, 46(9).

Yusoff, R.B. (2004). Growth Firm and Broad Based, Economic Planning Unit, Prime Minister's Office, Malaysia. [Online] Available: http://www.asiapacificbusiness.ca/peo/outlook2005/malaysia_05.pdf (April, 30 2007).

Zhang, Z., Waszink, Ab. \& Wijngaard, J. (2000). An instrument for measuring TQM implementation for Chinese manufacturing companies. International Journal of Quality and Reliability Management, 17(7), 730-755.

Zikmund, W.G.. (2000). Exploring Marketing Research, 7 th (eds), Dryden Press, Fort Worth. 


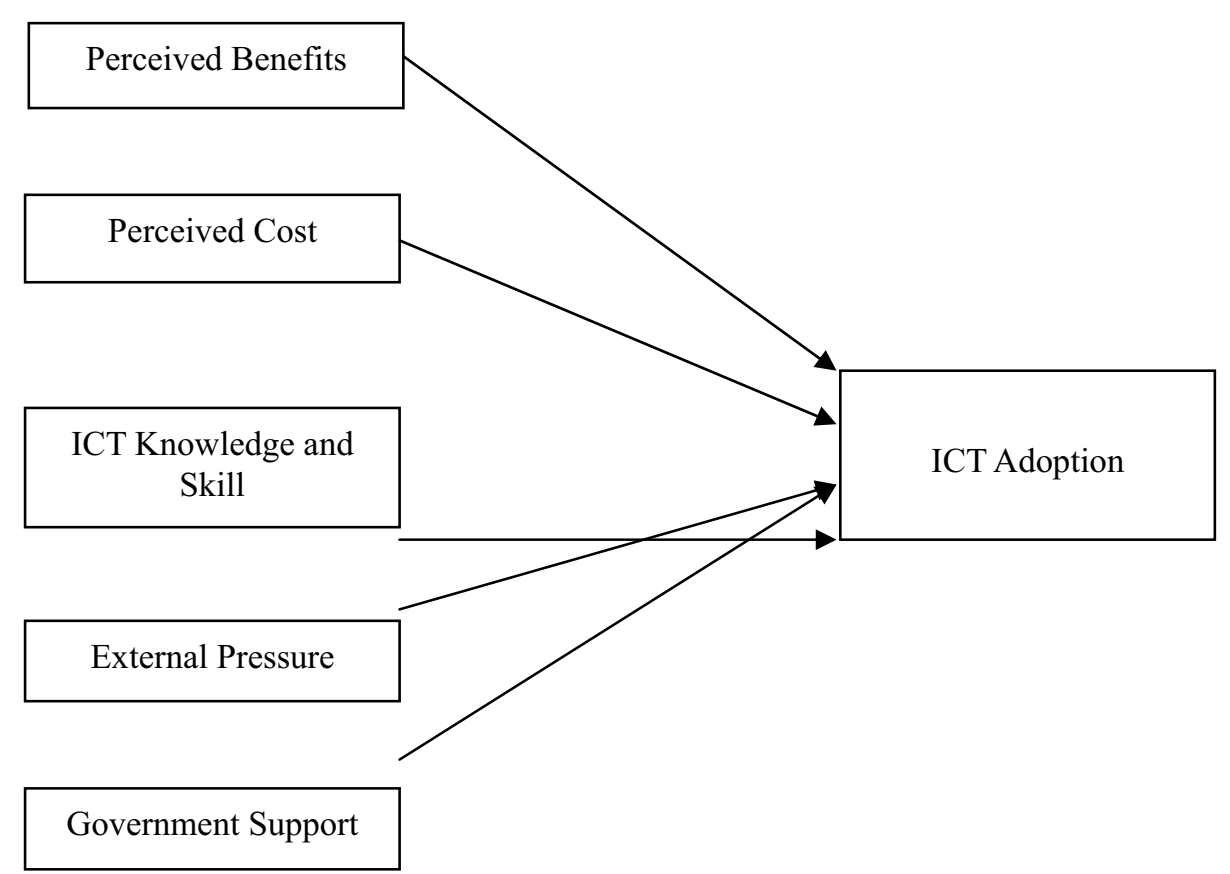

Figure 1. A Schematic diagram of the conceptual framework

Table 1. Hypotheses of this study

\begin{tabular}{|c|c|c|c|}
\hline No & \multicolumn{2}{|c|}{ Hypothesised Relationship } & HiA \\
\hline 1 & Perceived Benefits & ICT Adoption & $\mathrm{H}_{0} \mathrm{~A} \quad(+)$ \\
\hline 2 & Perceived Cost $\longrightarrow$ & ICT Adoption & $\mathrm{H}_{0} \mathrm{~A}$ \\
\hline 3 & ICT Knowledge and $\underset{\substack{\text { Skitts } \\
\text { Adoption }}}{\longrightarrow}$ & ICT & $\mathrm{H}_{0} \mathrm{~A} \quad(+)$ \\
\hline 4 & External Pressure & ICT Adoption & $\mathrm{H}_{0} \mathrm{~A}$ \\
\hline 5 & $\underset{\text { Adoption }}{\stackrel{\text { Government Support }}{\longrightarrow}}$ & ICT & $\mathrm{H}_{0} \mathrm{~A} \quad(+)$ \\
\hline
\end{tabular}


Table 2. Factor Analysis (Varimax) Showing the Combined Impacts on ICT adoption

\begin{tabular}{|c|c|c|c|c|c|c|}
\hline \multirow[b]{2}{*}{ Conditions } & \multirow[b]{2}{*}{ Factors/variables } & \multicolumn{5}{|c|}{ Factors } \\
\hline & & 1 & 2 & 3 & 4 & 5 \\
\hline \multirow[t]{6}{*}{ Perceived Benefits } & Benefit 1 & & & & .485 & \\
\hline & Benefit 2 & & & & .684 & \\
\hline & Benefit 3 & & & & .709 & \\
\hline & Benefit 4 & & & & .564 & \\
\hline & Benefit 5 & & & & .440 & \\
\hline & Benefit 6 & & .511 & & & \\
\hline \multirow[t]{4}{*}{ Perceived Cost } & Cost 1 & & .618 & & & \\
\hline & Cost 2 & & .565 & & & \\
\hline & Cost 3 & & .635 & & & \\
\hline & Cost 4 & & .550 & & & \\
\hline \multirow{6}{*}{$\begin{array}{l}\text { ICT Knowledge } \\
\text { and Skills }\end{array}$} & Skill 1 & & & .507 & & \\
\hline & Skill 2 & & & .676 & & \\
\hline & Skill 3 & & & .692 & & \\
\hline & Skill 4 & & & .602 & & \\
\hline & Skill 5 & & & .431 & & \\
\hline & Skill 6 & & & .573 & & \\
\hline \multirow[t]{6}{*}{ External Pressure } & Pressure 1 & .456 & & & & \\
\hline & Pressure 2 & .502 & & & & \\
\hline & Pressure 3 & .533 & & & & \\
\hline & Pressure 4 & .662 & & & & \\
\hline & Pressure 5 & .662 & & & & \\
\hline & Pressure 6 & .589 & & & & \\
\hline \multirow{5}{*}{$\begin{array}{l}\text { Government } \\
\text { Support }\end{array}$} & Support 1 & & & & & .546 \\
\hline & Support 2 & & & & & .687 \\
\hline & Support 3 & & & & & .677 \\
\hline & Support 4 & & & & & .714 \\
\hline & Support 5 & & & & & .572 \\
\hline
\end{tabular}

Extraction Method: Principal Axis Factoring.

Rotation Method: Varimax with Kaiser Normalisation. 
Table 3. General Profile of the SMEs

\begin{tabular}{|c|c|c|c|c|}
\hline No & Demographic Variables & $\begin{array}{c}\text { No. of } \\
\text { Respondents }\end{array}$ & $\%$ & Cumulative $\%$ \\
\hline \multirow[t]{8}{*}{1.} & Types of Business & & & \\
\hline & Wholesale and Retail & 86 & 47.78 & 47.78 \\
\hline & Selected Services & 37 & 20.55 & 68.33 \\
\hline & Professional firms & 25 & 13.89 & 82.22 \\
\hline & Transportation and logistics & 19 & 10.55 & 92.77 \\
\hline & Education and health & 08 & 4.44 & 97.21 \\
\hline & Computer industries & 03 & 1.66 & 98.87 \\
\hline & Telecommunication & 02 & 1.13 & 100.00 \\
\hline \multirow[t]{3}{*}{2.} & Ownership of the Company & & & \\
\hline & Local & 159 & 88.3 & 88.3 \\
\hline & Foreign & 21 & 11.7 & 100.0 \\
\hline \multirow[t]{5}{*}{3.} & Respondents position & & & \\
\hline & Owner, CEO & 10 & 5.6 & 5.6 \\
\hline & Manager & 23 & 12.8 & 18.4 \\
\hline & Mid level manager & 97 & 53.8 & 72.2 \\
\hline & Executive & 50 & 27.8 & 100.0 \\
\hline \multirow[t]{3}{*}{4.} & Computer Ownership & & & \\
\hline & Yes & 103 & 57.22 & 57.22 \\
\hline & No & 73 & 42.78 & 100.0 \\
\hline \multirow[t]{3}{*}{5.} & Internet Access at business & & & \\
\hline & Yes & 86 & 83.5 & 83.5 \\
\hline & No & 17 & 16.5 & 100.0 \\
\hline \multirow[t]{3}{*}{6.} & Length of Internet Access & & & \\
\hline & Less than 5 years & 59 & 57.28 & 57.28 \\
\hline & Above 5 years & 44 & 42.72 & 100.0 \\
\hline \multirow[t]{4}{*}{7.} & Operating systems usage & & & \\
\hline & Windows XP & 69 & 66.99 & 66.99 \\
\hline & Windows $2000 / 1998$ & 27 & 26.21 & 93.20 \\
\hline & Mac OS X & 02 & 6.80 & 100.0 \\
\hline
\end{tabular}

Table 4. Regression Results

\begin{tabular}{|c|c|c|c|c|}
\hline $\begin{array}{c}\text { Independent variables } \\
\text { Intercept }\end{array}$ & $\begin{array}{c}\text { Parameter } \\
\text { estimate }\end{array}$ & $\begin{array}{c}\text { Standard } \\
\text { error }\end{array}$ & t-value & p \\
\hline Perceived benefits** & .351 & .277 & 1.267 & .207 \\
\hline Perceived cost & .190 & .066 & 2.877 & .005 \\
\hline ICT knowledge and skill* & -.073 & .077 & -.948 & .344 \\
\hline External pressure & .189 & .075 & 2.518 & .013 \\
\hline Government support** & .127 & .072 & 1.758 & .080 \\
\hline \multicolumn{2}{|c|}{${ }^{*} \mathrm{p} \leq 0.05 ; * * \mathrm{p} \leq 0.01 ; \mathrm{N}=180$} & 6.928 & .0001 \\
\hline
\end{tabular}

